\title{
Drip Irrigation Salinity Management for Row Crops
}

BLAINE HANSON, University of California Irrigation and Drainage Specialist Emeritus, UC Davis; DON MAY, UCCE Farm Advisor Emeritus, Fresno County

In the past, California farmers have commonly used furrow and sprinkle irrigation to irrigate row crop plantings. More recently drip irrigation has come into increasing use in many other areas, including California's coastal valleys and the west side of the San Joaquin Valley. Growers in some of these areas encounter high soil salinity caused either by irrigation with saline water (in the coastal valleys) or upward flow of saline ground water (in many parts of the San Joaquin Valley).

Drip irrigation has the potential to increase crop yields with less irrigation water, and under saline conditions it has additional advantages over furrow and sprinkle irrigation systems. First, drip causes no foliar accumulation of salts during irrigation. Second, soil in the wetted area around emitters is mostly leached of salts, and that is often where root density is the highest, particularly for row crops. Third, high-frequency drip irrigation applications can maintain a relatively constant soil water content and soil salinity level over time near the drip lines.

A disadvantage of drip irrigation is that salt accumulates near the periphery of the wetted area. This salt accumulation can be a matter of concern if the emitter placement does not coincide reasonably well with the location of the plant row, particularly for crops that are sensitive or moderately sensitive to soil salinity. Salt accumulation above buried drip lines also is a concern.

Drip irrigation has been successful in the saline soils of the San Joaquin Valley. Experiments in commercial fields have proven subsurface drip irrigation of processing tomatoes to be a highly profitable practice (Hanson and May 2003, 2004), but if you want to reap the benefits of subsurface drip, you must also implement adequate salinity control. In this publication, we present guidelines for controlling salinity under drip irrigation. 


\section{Grop Response}

The effect of soil salinity on crop yields is generally shown by a crop tolerance graph that shows no effect on the yield until the soil salinity reaches a threshold limit, beyond which there is a linear decline in yield as soil salinity increases (Maas and Grattan 1999). The common way to measure the salinity of irrigation water or soil is to measure its electrical conductivity (EC), measured in deciSiemens per meter $(\mathrm{dS} / \mathrm{m})$. For soil salinity $\left(\mathrm{EC}_{\mathrm{e}}\right)$, you measure the $\mathrm{EC}$ of a saturated paste solution of soil and water extracted from the soil. Threshold soil salinity $\left(\mathrm{EC}_{\mathrm{t}}\right)$ is the highest $\mathrm{EC}_{\mathrm{e}}$ at which there is still no yield reduction. The relationship
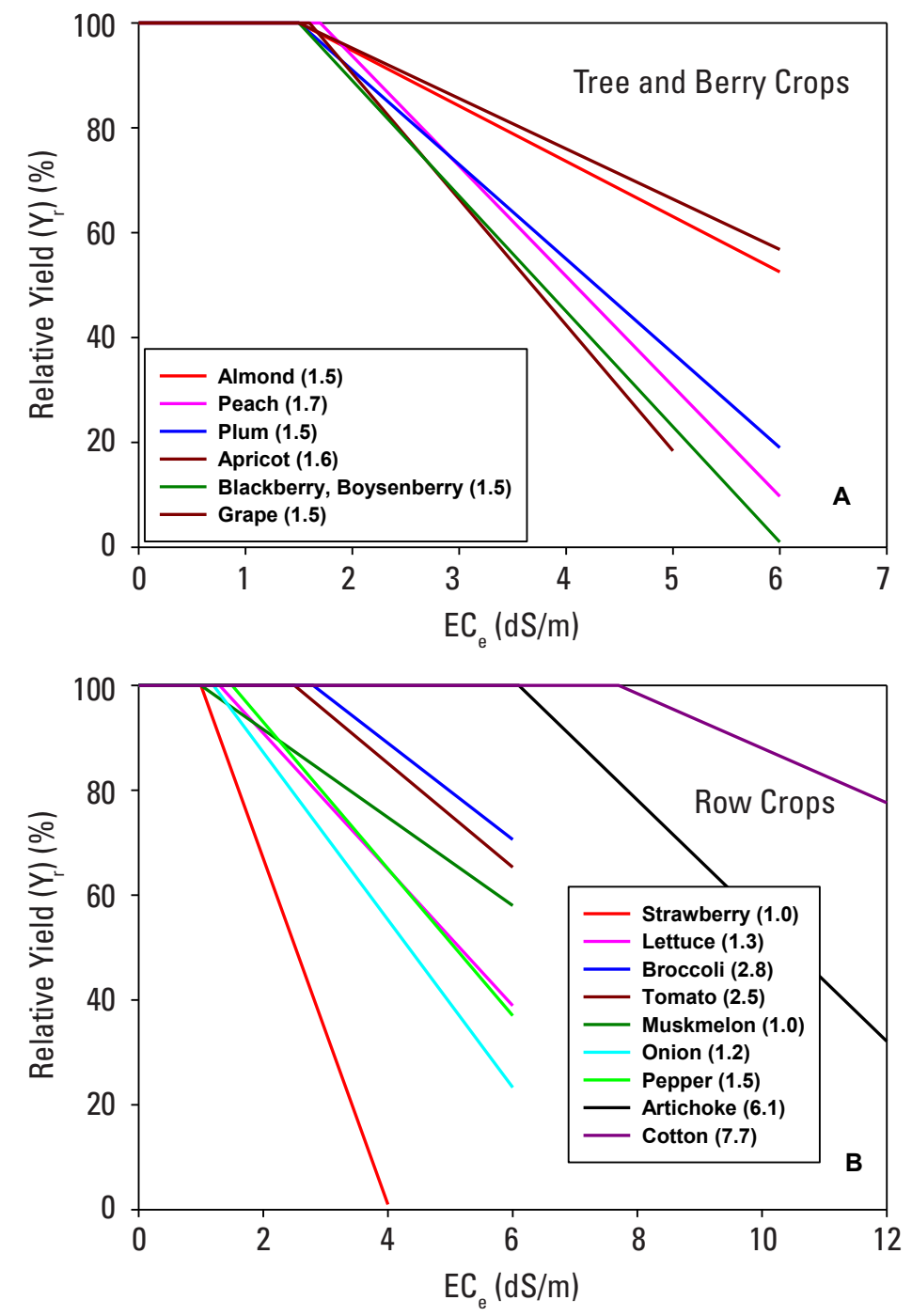

Figure 1. Crop salt tolerance relationships for (A) tree and berry crops and (B) row crops. between relative yield $\left(\mathrm{Y}_{\mathrm{r}}\right)$ and $\mathrm{EC}_{\mathrm{e}}$ is described by this equation:

$\mathrm{Y}_{\mathrm{r}}=100-\mathrm{b} \times\left(E C_{\mathrm{e}}-E C_{\mathrm{t}}\right)$

where $\mathrm{EC}_{\mathrm{t}}$ is the threshold soil salinity (Table 1 ) and $\mathrm{b}$ is the slope of the graphed line that describes the relationship between $\mathrm{Y}_{\mathrm{r}}$ and $\mathrm{EC}_{\mathrm{e}}$ (Table 1). Similar threshold values have been found for most tree crops (Figure 1A), demonstrating that most tree crops are sensitive to soil salinity (pistachio and olive trees are two exceptions). Threshold values vary considerably for row crops (Figure 1B), ranging from sensitive (strawberry and lettuce ) to moderately sensitive (tomato and broccoli) to salt tolerant (asparagus, artichoke, and cotton). Actual $\mathrm{EC}_{\mathrm{e}}$ threshold values may be 1 to $3 \mathrm{dS} / \mathrm{m}$ higher for gypsiferous soils (soils with large amounts of gypsum) than those shown in Table 1.

Table 1. Crop tolerance data for row crops likely to be grown with drip irrigation

\begin{tabular}{|lccc|}
\hline Crop & $\begin{array}{c}\mathrm{EC}_{\mathrm{t}} \text { (threshold } \\
\mathrm{EC}_{\mathrm{e}} \text { in dS/m) }\end{array}$ & Slope “b” & Rating* \\
\hline Artichoke & 6.1 & 11.5 & $\mathrm{MT}$ \\
Asparagus & 4.1 & 2.0 & $\mathrm{~T}$ \\
Broccoli & 2.8 & 9.2 & $\mathrm{MS}$ \\
Cabbage & 1.8 & 9.7 & $\mathrm{MS}$ \\
Carrot & 1.0 & 14.0 & $\mathrm{~S}$ \\
Celery & 1.8 & 6.2 & $\mathrm{MS}$ \\
Corn (sweet) & 1.7 & 12.0 & $\mathrm{MS}$ \\
Cotton & 7.7 & 5.2 & $\mathrm{~T}$ \\
Cucumber & 2.5 & 13.0 & $\mathrm{MS}$ \\
Garlic & 3.9 & 14.3 & $\mathrm{MS}$ \\
Lettuce & 1.3 & 13.0 & $\mathrm{~S}$ \\
Muskmelon & 1.0 & 8.4 & $\mathrm{MS}$ \\
Onion & 1.2 & 16.0 & $\mathrm{~S}$ \\
Pepper & 1.5 & 14.0 & $\mathrm{~S}$ \\
Spinach & 2.0 & 7.6 & $\mathrm{MS}$ \\
Strawberry & 1.0 & 33.0 & 9.9 \\
Tomato & 2.5 & & \\
\hline
\end{tabular}

* $\mathrm{S}=$ sensitive, $\mathrm{MS}=$ moderately sensitive, $\mathrm{MT}=$ moderately tolerant, $\mathrm{T}=$ tolerant Source: Maas and Grattan, 1999. 


\section{Does drip irrigation reduce soil salinity's effect?}

Data from Maas and Grattan (1999) come from studies using sprinkle or surface irrigation, many of which were conducted decades ago. For this reason, we reviewed more recent literature on the effect of soil salinity or irrigation water salinity on yield of drip-irrigated crops in order to understand the effect of drip irrigation on the salinityyield relationship.

Results of this review were mixed. Some studies showed that under drip irrigation the effect from soil salinity on yields of lettuce, onion, and potato was smaller than would be expected on the basis of earlier data. Other studies showed the yield response under drip irrigation for tomato, maize, and bell pepper to be similar to that predicted by the earlier data. Drip irrigation causes less foliar salt accumulation than sprinkle irrigation, so it can give better yields if the crop is sensitive to foliar salt (like peppers), while yields for more tolerant crops (like cotton) remain unchanged.

One complicating factor when you compare drip and non-drip systems is that soil salinity varies around drip lines, and that makes the estimation of salinity levels over time and distance more difficult. For these comparisons, the researchers used average soil salinity values over time near drip emitters for the root zone salinity levels. Another complicating factor is the difference in salt tolerance that is characteristic of different crop varieties. The varieties in use today may respond differently to salinity than those that were used decades ago, as illustrated by some recent studies. One study on the effect of salinity on the yields of 14 sweet corn cultivars showed yields that range from 54 to 82 percent of the maximum yield of each variety when the plants were irrigated with a $6.2 \mathrm{dS} / \mathrm{m}$ irrigation water (Pasternak et al. 1995). A recent study using 10 cultivars of processing tomatoes revealed relative yields ranging from 35 to 73 percent of the maximum yield of each variety for treatments that were drip-irrigated with a $6.0 \mathrm{dS} / \mathrm{m}$ irrigation water (Gawad et al. 2005). Because of the variety effect, it is difficult to make a blanket conclusion that drip irrigation will or will not reduce the effect of salinity on crop yield. Unfortunately, little information exists on the yield effects of varietal salt tolerance for crops grown in California.

\section{Salt Distribution around Drip Lines}

\section{Wetting patterns and root distribution}

Salt distribution around drip lines is a reflection of the wetting patterns during irrigation and the subsequent redistribution of soil water content. Wetting patterns around a surface drip line (Figure 2A) and a subsurface drip line (Figure 2B) just after an irrigation show that soil water content varies around the drip line. The wettest soil is near the drip line and the driest is at the periphery of the wetted pattern. 


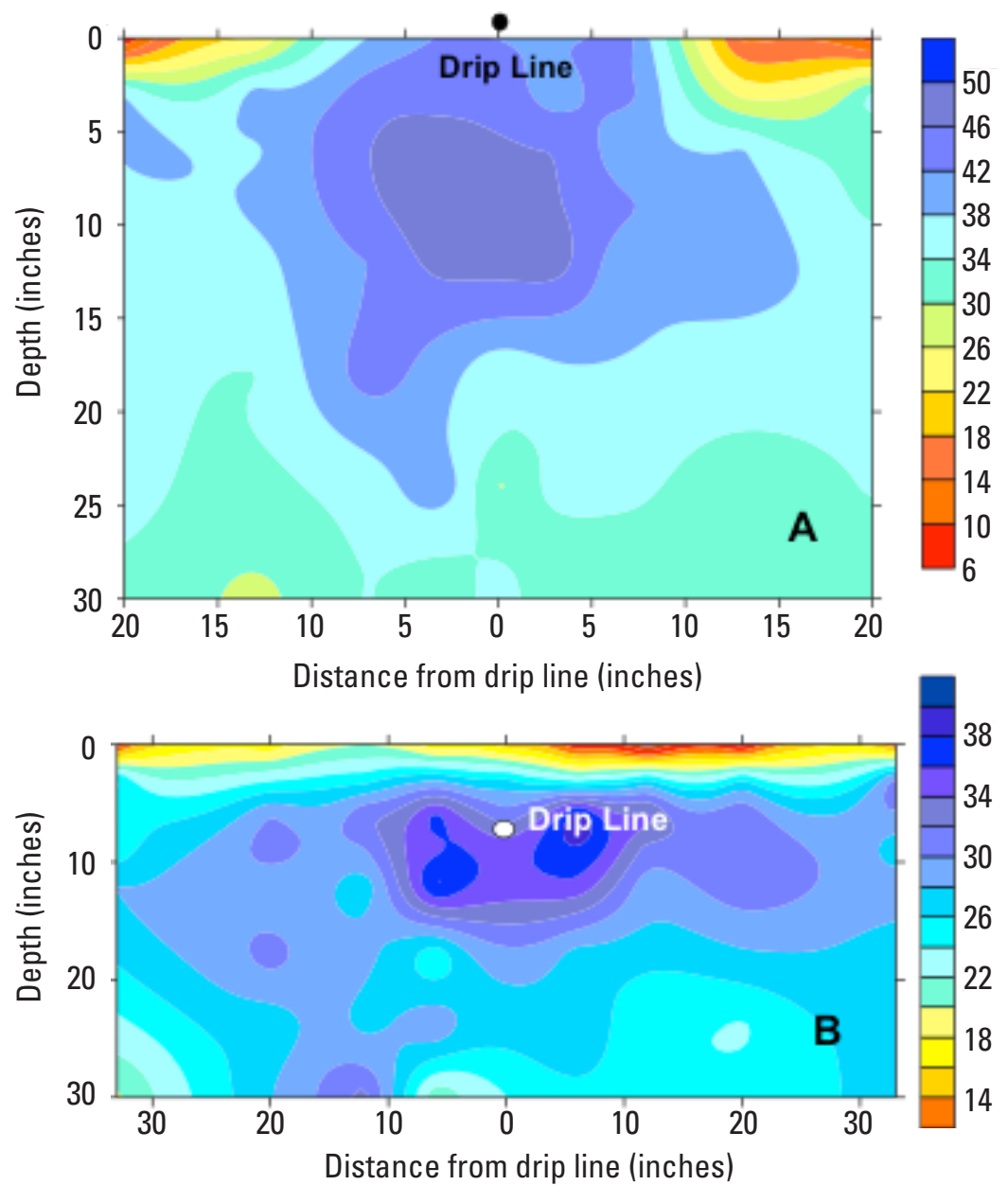

Figure 2. Soil moisture patterns around drip lines for (A) a surface drip line and (B) a subsurface drip line. Units in the color scale indicate percent volumetric moisture content.
Root distribution around drip lines also reflects wetting patterns. The roots of a row crop are highly concentrated near drip lines (the zone of wettest soil) if the drip line placement coincides with the plant row (Hanson and May 2007). Drip lines that are offset from plant rows may shift the zone of highest root density away from the drip line.

\section{Salt distribution}

Factors that affect root zone soil salinity under drip irrigation include the salinity of the irrigation water, the amount of water applied, the soil's hydraulic characteristics, the placement of drip lines relative to plant rows, and subsurface or surface placement of drip lines. Under saline, shallow groundwater conditions, the groundwater depth and salinity are also factors. Near the drip emitter, soil salinity will be the least and will reflect the salinity of the irrigation water. Soil salinity increases with distance from the emitter so that relatively large values can be detected near the periphery of the wetted pattern. Under subsurface drip irrigation, salt also accumulates above drip lines.

$\mathrm{EC}_{\mathrm{i}}$ indicates the electrical conductivity of an irrigation water. Under conditions found in commercial fields, irrigation with saline water $\left(\mathrm{EC}_{\mathrm{i}}\right.$ of 1.5 to $2.0 \mathrm{dS} / \mathrm{m}$ ) resulted in relatively low salinity levels in the area extending downward from surface drip lines and larger salt accumulations in the areas between drip lines and near the edge of the bed for sandy loam (Figure 3A) and clay loam (Figure 3B) soils. The low-salinity zone extended further horizontally in the clay loam soil than in the sandy loam. Under subsurface drip irrigation using saline water $\left(\mathrm{EC}_{\mathrm{i}}=2.5 \mathrm{dS} / \mathrm{m}\right)$, salt accumulated above the drip line, with the highest levels occurring near the soil surface (Figure 4). Soil salinity was lower around and below the drip line. 


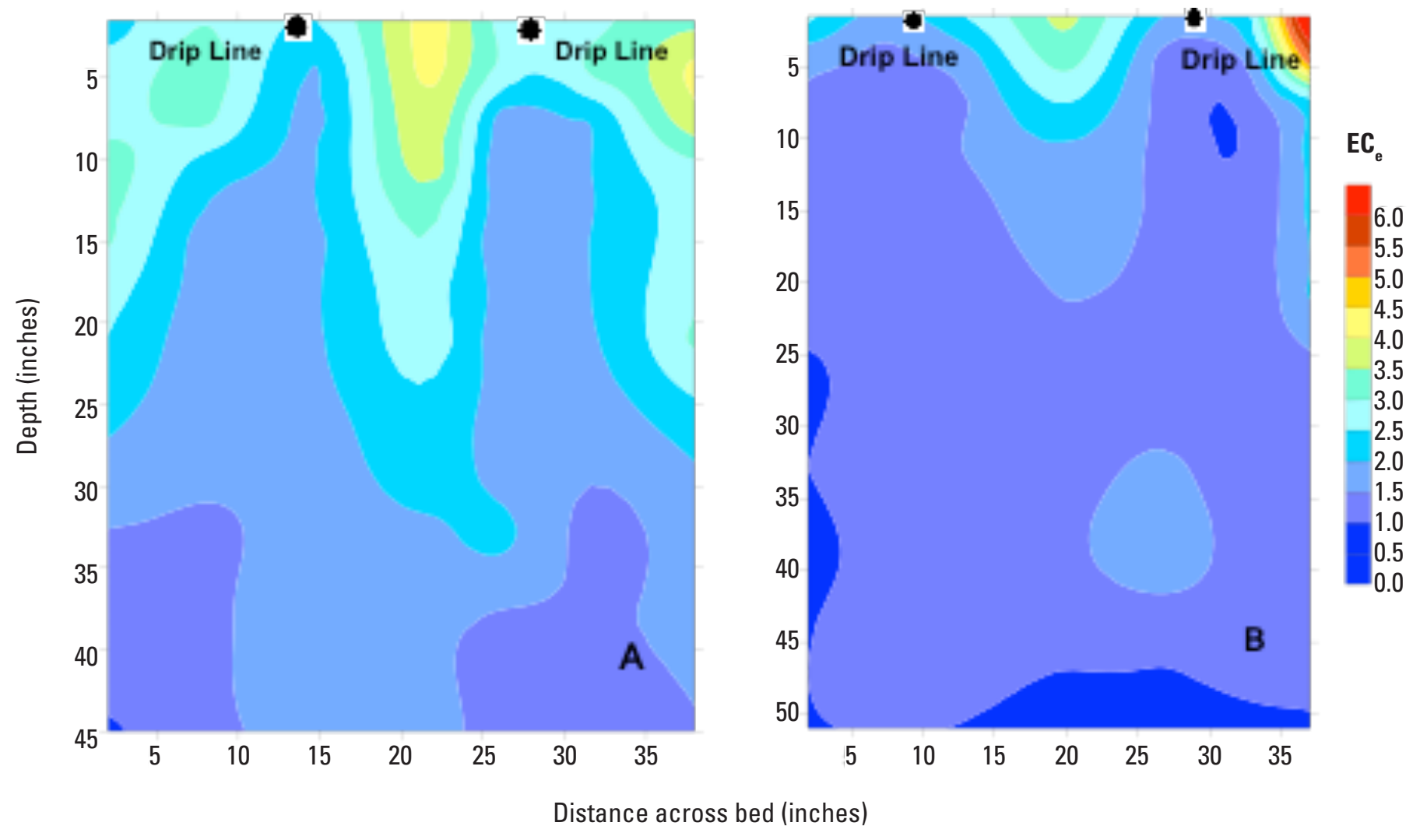

Figure 3. Salt distribution $\left(\mathrm{EC}_{\mathrm{e}}\right.$ ) around surface drip lines for $(\mathrm{A})$ sandy loam soil and (B) clay loam soil. Units are dS/m.

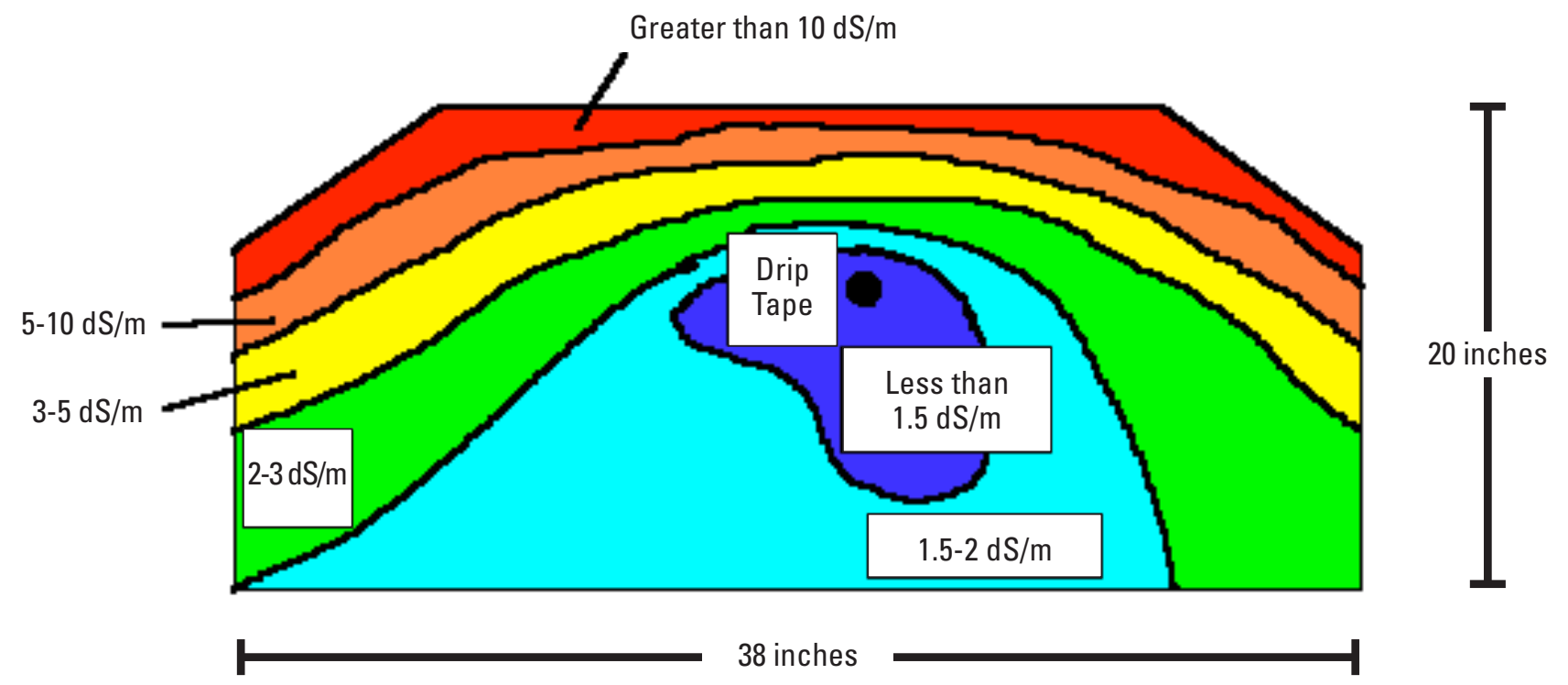

Figure 4. Salt distribution $\left(\mathrm{EC}_{\mathrm{e}}\right.$ ) around a subsurface drip line. Units are $\mathrm{dS} / \mathrm{m}$. 


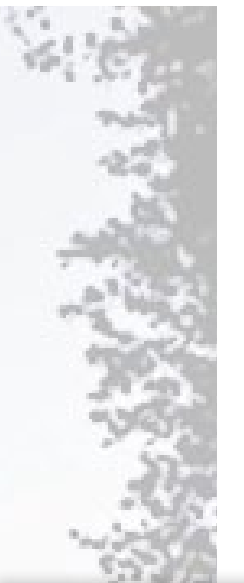

Under saline, shallow groundwater conditions such as exist along the west side of the San Joaquin Valley, the upward flow of saline groundwater may or may not affect root zone soil salinity, depending on the depth of the water table. A relatively uniform soil salinity profile was found in a clay loam soil with a water table depth of about 6 feet (Figure 5A) and a water $\mathrm{EC}_{\mathrm{i}}$ value of $0.3 \mathrm{dS} / \mathrm{m}$, indicating little upward flow from the

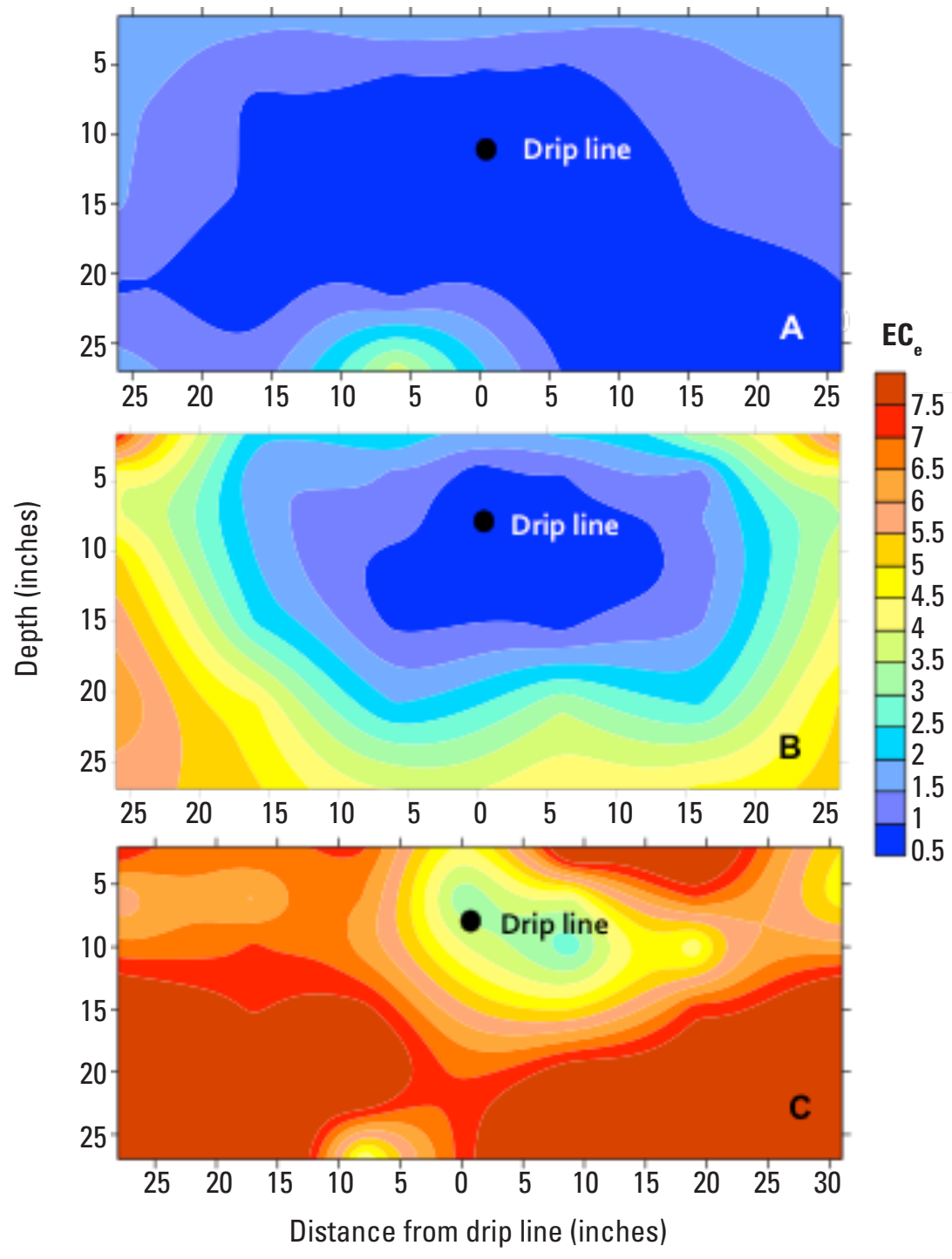

Figure 5. Salinity distribution $\left(\mathrm{EC}_{\mathrm{e}}\right) \mathrm{n}$ under saline, shallow groundwater conditions for $(\mathrm{A})$ a water table depth of 6 feet and irrigation water with an $\mathrm{EC}$ of $0.3 \mathrm{dS} / \mathrm{m},(B)$ a water table depth of about 3 feet and irrigation water with an EC of $0.3 \mathrm{dS} / \mathrm{m}$, and (C) a water table depth of about 3 feet and irrigation water with an $E C$ of $1.1 \mathrm{dS} / \mathrm{m}$. Units of the scale are $E C_{e}$ in $\mathrm{dS} / \mathrm{m}$. groundwater for that water table depth. Where the water was the same salinity but the water table was about 3 feet deep, soil salinity varied considerably with distance from the drip line (Figure 5B), with a relatively low soil salinity level near the drip line. Salinity levels near the edge of the wetting pattern reflected an upward flow of saline groundwater. Higher soil salinity levels near the drip line occurred with a higher-salinity irrigation water $\left(\mathrm{EC}_{\mathrm{i}}=1.1 \mathrm{dS} / \mathrm{m}\right)$ (Figure $\left.5 \mathrm{C}\right)$.

\section{Salinity Control}

The key to profitable drip irrigation under saline conditions is the control of salinity levels in the root zone. This involves leaching salts from the root zone by applying irrigation water in excess of the soil water depletion. The leaching fraction (the ratio of the amount of water that drains below the root zone and the amount of infiltrated water) is a measure of the adequacy of leaching.

The objective of leaching is to maintain soil salinity levels at, or reduce them to, levels that are equal to or less than the threshold soil salinity for your particular crop. Two strategies are commonly used: reclamation leaching and maintenance leaching.

\section{Reclamation leaching}

In reclamation leaching, you reduce excessive soil salinity (salinity that exceeds the threshold value) to values equal to or smaller than the threshold soil salinity of your particular crop. The specifics of a reclamation leaching program using drip irrigation consist of the amount applied per irrigation, the frequency of irrigations, and the length of the reclamation period. One study of an initially saline soil showed that water applications applied twice per week reclaimed the soil more quickly 


\section{$3 t^{3}=$ than the same amount of water divided into smaller, daily applications (Hanson, Hopmans, and Simunek 2008). At both frequencies, however, the volume of low-salinity soil near drip lines increased over time, eventually becoming similar in volume. During the reclamation period, the amount of leaching water per irrigation was constant but the salinity of the leaching water percolating below the root zone decreased over time as the zone of low-salinity soil expanded. \\ Maintenance leaching}

For maintenance leaching, you control soil salinity in the root zone throughout a crop season so as to prevent the soil salinity near drip lines from exceeding the threshold soil salinity for the crop. This requires that you apply sufficient irrigation water at a high enough frequency to guarantee adequate leaching in the root zone. Irrigation frequencies of two to three times per week may be sufficient for crops that are at least moderately sensitive to salinity. Daily irrigations may be required for salt-sensitive crops.

In areas with shallow, saline groundwater, you have to manage drip-irrigation systems carefully to maintain sufficient root zone leaching and at the same time prevent saline groundwater from encroaching into the root zone as a result of a rising water table. Field experience has shown that drip irrigation is feasible for processing tomatoes under very shallow, saline groundwater conditions (where the water table is between 18 and 24 inches deep) when you use daily drip irrigation applications, but the amount of applied water should be equal to the crop's evapotranspiration between irrigations and the depth to groundwater should be continuously monitored (Hanson, Hutmacher, and May 2006).

\section{Leaching considerations}

The application of sufficient water via drip irrigation results in highly concentrated leaching near the drip lines, a phenomenon known as localized leaching. (The term "localized leaching" is used because most of the leaching occurs near the drip lines, in contrast to the leaching typical of sprinkle and flood irrigation systems, where leaching occurs throughout the entire soil profile.) Soil salinity is the lowest in this highly leached zone and is a fairly accurate reflection of the irrigation water's own salinity (Figure 6A). Leaching decreases with distance from drip lines, with no leaching midway between adjacent drip lines. There, the soil salinity is the highest. This leaching pattern reflects the natural pattern of wetting in the soil during drip irrigation. If, however, the volume of applied water is too small, salt can accumulate near drip lines when you irrigate with saline water (Figure 6B). An increase in the volume of applied water also increases the zone of low-salinity soil around drip lines (Figure 7).

Research has shown that, for surface drip irrigation, an increase in the leaching fraction also increases the crop yield for many vegetable crops, including celery, cauliflower, lettuce, cowpea, and tomato (Hoffman et al. 1979; Hoffman and Jobes 1983; Jobes, Hoffman, and Wood 1981). Other researchers found similar correlations for subsurface drip-irrigated processing tomatoes in the San Joaquin Valley (Hanson and May 2004; Hanson, Hutmacher, and May 2006). This phenomenon is caused by a combination of lower soil salinity near the drip lines, a larger zone of low-salt soil around the drip lines, and a higher soil water content near the drip lines, with an increased leaching fraction resulting from an increase in the quantity of applied water. 


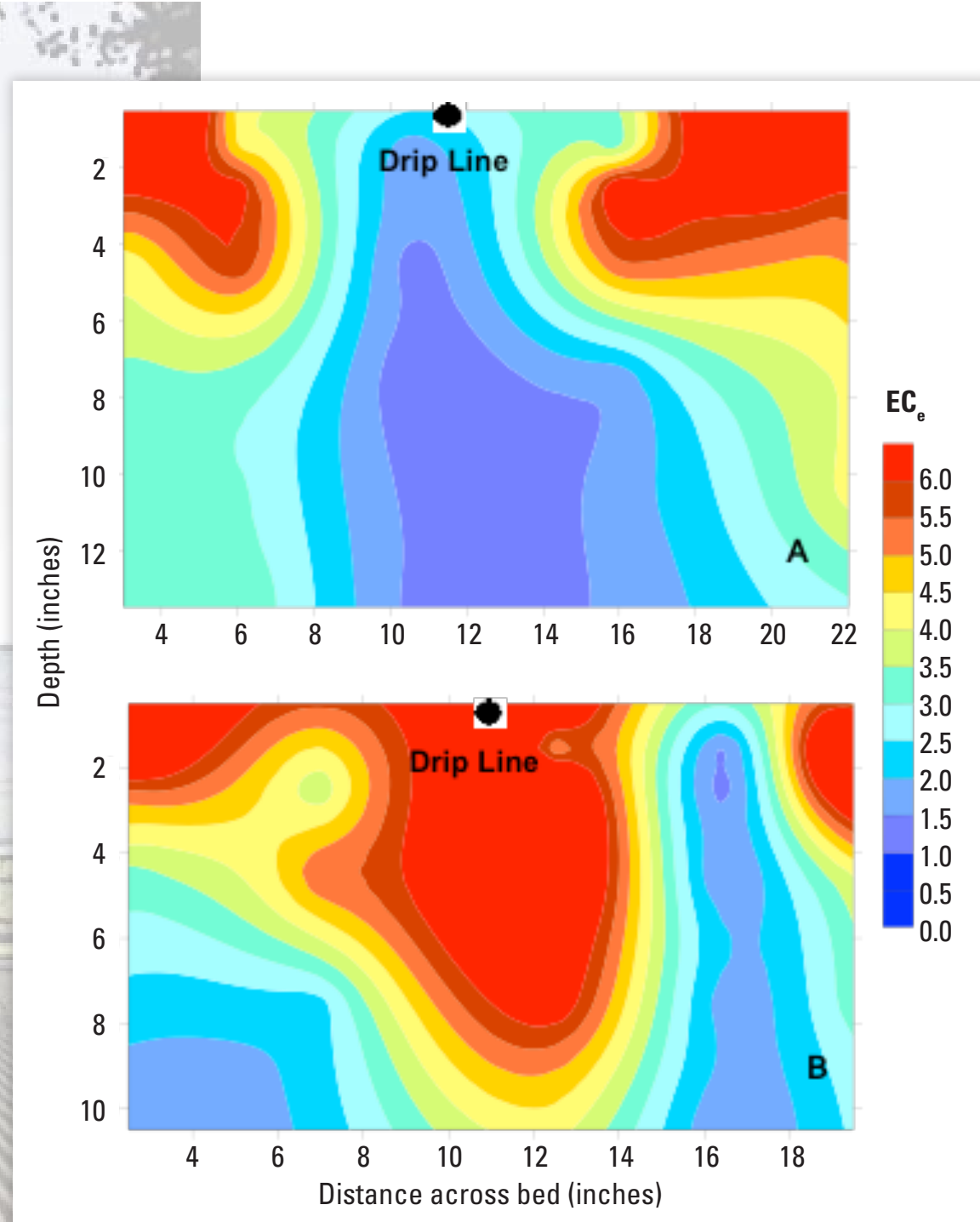

Figure 6. Salinity distribution $\left(E C_{e}\right)$ for $(A)$ leaching around the drip line and $(B)$ no leaching around the drip line. Units of the scale are dS/m.

The zone of highly leached soil may be relatively small for sandy soils when compared to fine-textured soils, as illustrated in Figure 3. There was more relatively low-salt soil in the soil profile for the clay loam soil than for the sandy loam soil.

Water flows upward from drip lines in a subsurface drip-irrigation system. Thus, no leaching occurs above the buried drip lines, resulting in an accumulation of salt near the soil surface, as illustrated in Figures 4 and 5. Periodic leaching from either rainfall or sprinkle irrigation is necessary to control root zone soil salinity above the drip lines. Sufficient leaching water should be applied to move the salts below the drip line, where they will eventually leach with subsequent drip irrigations. Failure to move the salts below the drip lines will result in their re-accumulation above the drip lines.

The placement of drip lines relative to plant rows is critical to salinity control with drip irrigation, particularly for salt-sensitive row crops. Salinity control will be best where drip lines and plant rows coincide, since the root density of row crops generally will be greatest near the drip lines where leaching will also be greatest (this may not be the case for tree or vine crops). When you offset the drip lines from the plant rows, you can shift the zone of highest root density away from the most highly leached soil. In some cases, you end up putting most of the roots in areas of higher soil salinity. The leaching pattern under drip irrigation and its effect on the pattern of soil salinity should be a consideration when you replace drip lines, and buried drip lines in particular. Under subsurface drip irrigation, drip lines and beds may remain in the same place for many years, with the potential that you will create a zone of very high salinity midway between the drip lines. New drip lines should be placed as close as possible to the locations of the old drip lines in order to keep the root zone from encroaching into this zone of potential high soil salinity. If you do place new drip lines in the high-salinity zone, you may have to conduct reclamation leaching in advance of the crop season. 


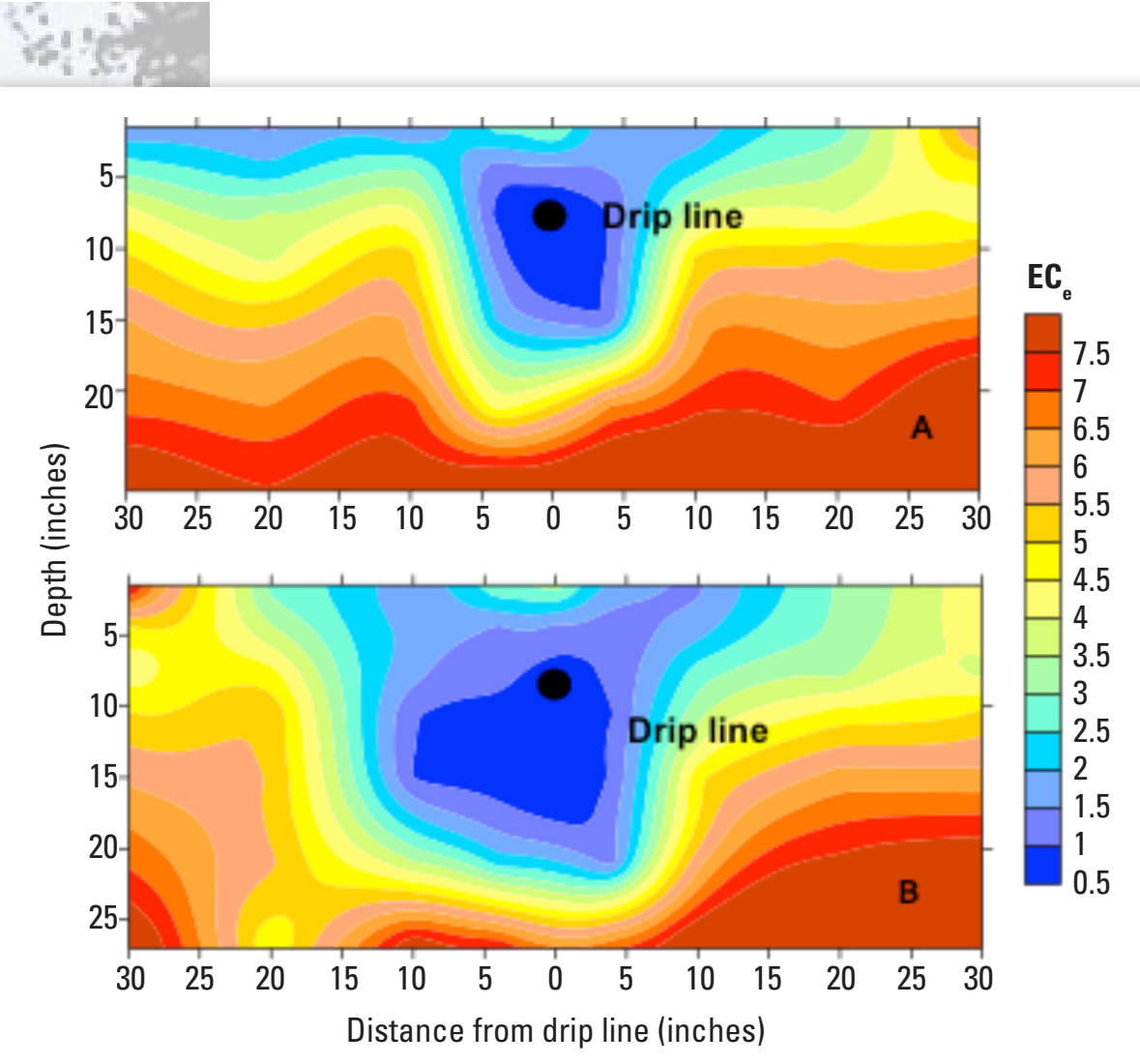

Figure 7. Soil salinity $\left(E C_{e}\right)$ patterns around a drip line for $(A) 12$ inches of applied water, and (B) 19 inches of applied water. The low-salt zone around the drip line is larger for the higher amount of applied water. The high levels of soil salinity below the low-salt zones are due to the upward flow of shallow saline groundwater.

\section{Estimating the Leaching Fraction}

Several methods have been used in the past to determine the leaching fraction in commercial fields. One method involves measuring the irrigation water $\mathrm{EC}$ and the average root zone soil salinity $\left(\mathrm{EC}_{\mathrm{e}}\right)$. Sometimes, chloride concentration are used instead of EC. These data are then used to derive the leaching fraction using leaching curves or appropriate equations. These equations, however, were developed for flood and sprinkle irrigation. Because both salt and root patterns vary horizontally as well as vertically around drip lines, the old equations may not yield results that are useful for a drip-irrigated field.
Another approach is the water balance method, commonly used to estimate fieldwide leaching fractions by means of comparing the cumulative amounts of applied water and evapotranspiration for a given time period. The amount of water available for leaching is the difference between applied water and evapotranspiration, assuming that the soil moisture is at field capacity at the start of the crop season. Again, though, field studies indicate that the water balance method may be inappropriate for drip irrigation because it does not account for the effect that the wetting pattern around the drip line has on leaching. This wetting can cause more leaching near drip lines than would be estimated by the water balance method, even under deficit irrigation (when the total applied water is less than 100 percent of evapotranspiration). Two studies support this conclusion.

A USDA ARS study conducted in western Fresno County estimated actual leaching fractions for dripirrigated almonds in silt loam to clay loam soil, measured in terms of soil chloride concentrations (Nightingale et al. 1991). Amounts of applied irrigation water were 50, 100, and 150 percent of the estimated evapotranspiration for the almond trees. The water balance method would indicate that no leaching should occur for the 50 and 100 percent applied water treatments and that a 50 percent leaching fraction should occur for the 150 percent treatment, but actual leaching fractions 


\section{Sun $\quad$ were 4 to 6 percent for the 50 percent water treat- ment, 10 to 22 percent for the 100 percent treat- ment, and 31 to 36 percent for the 150 percent treatment. The soil was well reclaimed before the start of this trial and the trees had been estab- lished on low-salinity water for 3 years prior, and then irrigated with saline water for 4 years before the researchers obtaining these results. \\ A second study conducted out of UC Davis showed that under saline shallow groundwater conditions, the fieldwide amounts calculated for leaching by means of the water balance method revealed little or no fieldwide leaching in four fields of processing tomatoes, suggesting that there was inadequate salinity control and raising questions about the long-term viability of drip irrigation under saline conditions (Hanson and May 2004, Hanson et al. 2009). The soil salinity data, however, clearly showed substantial localized leaching around drip lines and showed that the overall leaching was concentrated near the drip lines (Figure 5B and 5C). Computer simulations revealed actual or localized leaching fractions of 7.7, 24.5, and 30.5 percent for water applications of 60,100 , and 115 percent of the estimated evapo- transpiration for the processing tomatoes (Hanson, Hopmans, and Simunek 2008). Even for water applications that would conventionally be consid- ered severe deficit irrigation, the drip system still caused drainage below the root zone as a result of the wetting patterns under drip irrigation.}

\section{Monitoring Soil Salinity}

Estimation of actual leaching fractions under drip irrigation may be difficult because leaching varies throughout the wetting pattern that surounds a drip line. It makes sense, though, to monitor soil salinity over time to determine whether leaching is sufficient. Because soil salinity varies with distance from drip lines, the sampling location is important. One approach is to collect soil samples near the drip lines, determine the $\mathrm{EC}_{\mathrm{e}}$ of the samples, and compare these $\mathrm{EC}_{\mathrm{e}}$ values to the threshold salinity of the crop. Soil sample values that are higher than the threshold levels may indicate insufficient leaching. For row crop drip systems where the drip line location coincides with plant rows, we recommend taking samples within the first 6 inches from the drip line because research has shown that most of the roots will be found near the drip lines.

The actual $\mathrm{EC}_{\mathrm{e}}$ must be determined on the basis of a laboratory analysis. Note that some laboratories measure soil salinity using a paste of soil and water in ratios such as 1:5 or 1:10. EC values determined using these ratios will differ from those determined from $\mathrm{EC}_{\mathrm{e}}$ for a given soil salinity. While you can use these values to monitor soil salinity over time, they cannot be used with the values listed in Table 1, which were determined from $\mathrm{EC}_{\mathrm{e}}$ data. It is important that you use $\mathrm{EC}_{\mathrm{e}}$ values to determine soil salinity, since a crop's yield response is based on $\mathrm{EC}_{\mathrm{e}}$. 


\section{Final Considerations}

Here are a few things to consider as you develop a plan for salinity control under drip irrigation:

- Based on the research results cited in this publication, your water applications should be at least equal to the crop evapotranspiration. This amount of water appears to provide sufficient localized leaching. Based on research results, application of an amount of water about equal to the crop evapotranspiration will result in a leaching fraction of about 10 to 25 percent, most of it occurring around and directly beneath the drip line. Water applications in excess of crop evapotranspiration under shallow groundwater conditions may cause the intrusion of saline groundwater into the root zone.

- The electrical conductivity of the low-salt soil near drip lines will reflect the electrical conductivity of the irrigation water. The effect of the irrigation water salinity on crop yield will depend on the crop's level of salt tolerance and the amount of leaching. Water applications in excess of crop evapostranspiration may be necessary in an adequately drained soil in order to reduce the effect of the irrigation water's salinity on crop yield. Because it is so difficult to estimate localized leaching fractions, you may have to use a trial-and-error process to determine the optimal leaching fraction for a given irrigation water salinity.

- By placing drip lines near plant rows, you can take advantage of the low-salt zone and the tendency for root patterns to develop near drip lines. Drip lines that are offset from plant rows may result in higher rootzone soil salinity Periodic sprinkle-irrigation leaching of salt that accumulates above the buried drip lines will be necessary for stand establishment if winter and spring rainfall levels are too low.

- Drip-irrigation systems should be designed for a highly uniform application of water in order to ensure adequate leaching throughout most of the field.

- Drip-irrigation systems should be properly maintained to prevent clogging of emitters, since any clogging will reduce the leaching fraction. Detailed information on clogging prevention and correction are in Maintaining Microirrigation Systems (UC ANR Publication 21637). 


\section{References}

Gawad, G. A., A. Arslan, A. Gaihbe, and F. Kadouri. 2005. The effects of saline irrigation water management and salt tolerant tomato varieties on sustainable production of tomato in Syria (1999-2002). Agricultural Water Management 78:39-53.

Hanson, B. R., J. W. Hopmans, and J. Simunek. 2008. Leaching with subsurface drip irrigation under saline, shallow groundwater conditions. Vadose Zone Journal 7(2):1-9.

Hanson, B. R., R. B. Hutmacher, and D. M. May. 2006. Drip irrigation of tomato and cotton under shallow saline ground water conditions. Irrigation and Drainage Systems 20:155-175.

Hanson, B. R., and D. M. May. 2003. Drip irrigation increases tomato yields in salt-affected soil of San Joaquin Valley. California Agriculture 57(4):132-137.

- 2004. Effect of subsurface drip irrigation on processing tomato yield, water table depth, soil salinity, and profitability. Agricultural Water Management 68:1-17.

- 2007. The effect of drip line placement on yield and quality of drip-irrigated processing tomatoes. Irrigation and Drainage Systems 21(2):109-118.

Hanson, B. R., D. M. May, J. Simunek, and J. W. Hopmans. 2009. Drip irrigation provides the salinity control needed for profitable irrigation of tomatoes in the San Joaquin Valley. California Agriculture 63(3):131-136.

Hoffman, G. J., and J. A. Jobes. 1983. Leaching requirement for salinity control. III. Barley, cowpea, and celery. Agricultural Water Management 6:1-14.

Hoffman, G. J., S. L. Rawlins, J. D. Oster, J. A. Jobes, and S. D. Merrill. 1979. Leaching requirement for salinity control. I. Wheat, sorghum, and lettuce. Agricultural Water Management 2:177-192.

Jobes, J. A., G. J. Hoffman, and J. D. Wood. 1981. Leaching requirement for salinity control. II. Oat, tomato, and cauliflower. Agricultural Water Management 4:393-407.

Maas, E. V. 1990. Crop salt tolerance. In K. K. Tanji, ed., Agricultural salinity assessment and management. New York: American Society of Civil Engineers, Manuals and Reports on Engineering Practices No. 71.

Maas, E. V., and S. R. Grattan. 1999. Crop yields as affected by salinity. In R. W. Skaggs and J. van Schilfgaarde, eds., Agricultural drainage. Madison, WI: ASA, CSSA, SSA. Agron. Monograph 38. Pp. 55-108.

Nightingale, H. I., G. J. Hoffman, D. E. Rolston, and J. W. Biggar. 1991. Trickle irrigation water rates and soil salinity distribution in an almond (Prunus amygdalus) orchard. Agricultural Water Management 19:271-283.

Pasternak, D., M. Sagih, Y. De Malach, Y. Keren, and A. Shaffer. 1995. Irrigation with brackish water under desert conditions XI. Salt tolerance in sweet-corn cultivars. Agricultural Water Management 28:325-334.

Schwankl, L., B. Hanson, and T. Prichard. 2008. Maintaining microirrigation systems. Oakland: University of California Division of Agriculture and Natural Resources Publication 21637. 


\section{For More Information}

To order or obtain ANR publications and other products, visit the ANR Communication Services online catalog at http://anrcatalog. ucdavis.edu or phone 1-800-994-8849. You can also place orders by mail or FAX, or request a printed catalog of our products from

University of California

Agriculture and Natural Resources

Communication Services

1301 S. 46th Street

Building 478 - MC 3580

Richmond, CA 94804-4600

Telephone 1-800-994-8849

510-665-2195

FAX 510-665-3427

E-mail:anrcatalog@ucdavis.edu

(C)2011 The Regents of the University of California

Agriculture and Natural Resources

All rights reserved.

Publication 8447

ISBN-13: 987-1-60107-740-0

The University of California prohibits discrimination or harassment of any person on the basis of race, color, national origin, religion, sex, gender identity, pregnancy (including childbirth, and medical conditions related to pregnancy or childbirth), physical or mental disability, medical condition (cancer-related or genetic characteristics), ancestry, marital status, age, sexual orientation, citizenship, or service in the uniformed services (as defined by the Uniformed Services Employment and Reemployment Rights Act of 1994: service in the uniformed services includes membership, application for membership, performance of service, application for service, or obligation for service in the uniformed services) in any of its programs or activities.
University policy also prohibits reprisal or retaliation against any person in any of its programs or activities for making a complaint of discrimination or sexual harassment or for using or participating in the investigation or resolution process of any such complaint.

University policy is intended to be consistent with the provisions of applicable State and Federal laws.

Inquiries regarding the University's nondiscrimination policies may be directed to the Affirmative Action/Equal Opportunity Director, University of California, Agriculture and Natural Resources, 1111 Franklin Street, $6^{\text {th }}$ Floor, Oakland, CA 94607, (510) 987-0096. For information about ordering this publication, telephone 1-800-994-8849. For assistance in downloading this publication, telephone 530-754-3927.

To simplify information, trade names of products have been used. No endorsement of named or illustrated products is intended, nor is criticism implied of similar products that are not mentioned or illustrated.

An electronic copy of this publication can be found at the ANR Communication Services catalog Web site, http://anrcatalog. ucdavis.edu.

UC PEER V

REVIEWED This publication has been anonymously peer reviewed for technical accuracy by University of California scientists and other qualified professionals. This review process was managed by ANR Associate Editor for Land, Air, and Water Sciences Anthony T. O'Geen.

web-6/11-WJC/RW 